\title{
Who Cares? Social Roles and Attempts to Modify Behavioral Strategies through Service Provider Presentations
}

\author{
Erica Jablonski \\ Department of Sociology, College of Liberal Arts, University of New Hampshire, United States
}

Copyright $(2017$ by authors, all rights reserved. Authors agree that this article remains permanently open access under the terms of the Creative Commons Attribution License 4.0 International License

\begin{abstract}
In this participation observation study conducted in the northeastern United States, I used Erving Goffman's theories on the presentation of self in everyday life and on stigma to analyze the content and relative success of five service provider presentations about issues relevant to people with disabilities or older adults needing assistance to live independently. A stated goal of all presentations was to increase understanding of the needs of the populations served, but it was apparent that the purpose of increased understanding was to reinforce prosocial behaviors toward service users. In other words, service provider presentations were socialization events seeking to engage attendees in enhanced positive social interactions with the subjects of each presentation. Audience member engagement at the presentations varied based on the social roles of audience members, their stance relative to the populations discussed, and the extent to which the presentations pushed them to accept redefined social roles and behaviors. By analyzing the positive, negative, engaged, and detached nature of social exchanges in these presentations, it may be possible to reveal more and less effective ways that service providers can help modify the interaction rituals between social actors and stigmatized populations.
\end{abstract}

Keywords Social Roles, Stigma, Service Providers, Functioning, Disability, Participant Observation, Service Users

\section{Introduction}

The percentage of Americans with a disability who require functional assistance or participatory assistance increased between 2005 and 2010[1]. According to the World Health Organization, projected growth in this population stems largely from aging, because older people have a higher risk of disability, and chronic health conditions associated with disability[2,3]. The United States will face increasing demand for long-term care services from this population[4] but will have an insufficient supply of professional and family caregivers[5,6].

Despite growing services demands, recent actions have been taken to reduce Social Security, Medicare [7], and Medicaid, and to repeal the Affordable Care Act[8] support programs. To protect older adults and disabled individuals these programs were designed for, the public and service providers need to be fully informed about their needs, risks and struggles. Although care advocates and organizations have arisen to promote more public funding (e.g., policy proposals), public support for care work for is lacking[9]. The public's reluctance to support care policies has been attributed to the American tradition of independence and designation of care activities as an individual versus collective responsibility [9].

Though almost all members of society fall into one of four care movement stakeholder groups - paid caregivers, unpaid caregivers, care recipients, or friends and families of those in the other groups - the lack of mobilization for care-related issues highlights a lack of identification and responsibility for caregivers and care recipients [9].Scholars have found that intergroup contact diminishes prejudice between groups $[10,11]$, but barriers to engagement with dissimilar others must be overcome. Because research has confirmed that a person's affinity with a group centers on the extent of perceived similarity between a person and that group [12], humanizing an out-group can reduce discrimination against it[13]. Attitudes and behaviors of social service providers toward service users are particularly crucial because service providers not only determine needed services but, in trying to acquire services, must also educate others, and advocates for policy change [14].

Prior research has analyzed policy formation[15] and case management discussions of service providers[16,17] for older adults and people with disabilities, but little research has focused on how providers convey clients' needs to various audiences. Service provider presentations offer a 
glimpse into the perspectives of provider organizations and their employees who work directly with these populations. Although provider interviews and observations of case management meetings can reveal individual providers' perspectives and how they enact their professional roles, formal presentations epitomize a group socialization function.

I attended and analyzed the content of five presentations: Living with Disabilities, Alzheimer's Disease, Aging Loved Ones' Safety at Home, Protective Services, and Food Safety. Because the content of each presentation was unique, a field note analysis identified common features, after which a second analysis of each presentation's success was done. A final analysis examined presenter-audience interactions to account for observed differences in audience reactions. The overall aim was to uncover ways that service providers presented issues their clients faced to generate greater understanding of clients and their problems and to improve social interactions with them.

\section{Literature Review}

There is conflicting information about the extent to which service providers' perspectives on what is in their clients' best interests varies from their clients or clients' families. Launay found that elderly patients' and family members' quality-of-care conceptions were similar, but differed from professional caregivers' perceptions [18]. In contrast, MacLeod and Stadnyk[16] concluded that professional service providers' needs assessments aligned to their clients' assessments more than with family members, who might assess acceptable risk more rigidly, and with less consideration for patient autonomy. Complicating matters further, McDermott[17] reported that professional evaluations of risk and capacity differed based on whether service providers worked for health- or housing-related programs. These last two studies of professional risk assessments, neglected client perspectives, while McDermott's analysis omitted the family's perspective. Moreover, McFarlane[19] described how disabled people can feel detached from decision-making that governs their own lives, and continuing care retirement community residents have similarly described transitioning from independent living to assisted living, especially to skilled nursing, as isolating and disempowering[20].

Symbolic interactionism frames the effects of socialization efforts such as service provider presentations because of its core assumptions that humans behave based on the meanings they attribute to things (including people), that these meanings are based on social interactions with others, and that people process these social meanings to determine how to respond in a given situation[21]. Symbolic interactionism, according to Mead, summarizes the inherent human interdependence on others to form our identities[22]. Mead described the socialization process of the self as developing because of and through an individual's interactions with others and interpretations of those interactions[22]. Although Mead claimed that "[t]he essence of the self . . is cognitive," the impressions of others informs our perceptions of facts, values and emotions. As Cooley[23] explained, "the character and weight of [the imagined] other, in whose mind we see ourselves, makes all the difference with our [self] feeling."

Goffman's more general theories of social roles and personal interactions further explain the perspectives of those who receive and provide services, and those who do neither. All people are social actors whose interactions depend on conventional routines[24]. The established "scripts" for each routine are based on the social roles of actors relative to each other in a particular setting and "tend to incorporate and exemplify the officially accredited values of the society"[24]. In light of his dramaturgical metaphor, Goffman's conceptualization of social interactions is particularly appropriate for analysis of presentations to live audiences. In this context, whether a social actor's performance is successful relies on the audience's reaction to the message(s) the actor is trying to transmit. In the case of service provider presentations about service users, therefore, the social roles of the audience members as they personify "the rights and duties attached to a given status" can be expected to influence their reactions to what is presented.

Goffman's theories pertaining to stigma are also relevant to this analysis, because of his characterization that someone who is "different from others" in an undesirable way "is reduced in our minds from a whole and usual person to a tainted, discounted one"[25]. As a result of this categorization, so-called normals "exercise varieties of discrimination, through which we effectively, if often unthinkingly, reduce [a stigmatized person's] life chances"[25]. It is precisely for this reason, Goffman argues, that society endorses "benevolent social action ... designed to soften and ameliorate . . attitudes . . . and the actions we take in regard to ... a person with a stigma"[25]. With increasing social and political polarization, when family and religion, which traditionally conveyed such moral scripts, are supposedly declining in influence, secondary institutions (e.g., schools and workplaces) have become sites of moral socialization. Given the heavy responsibility located in these institutions, it is important to assess how well these new moral socializers, including service providers to the functionally impaired, are accomplishing this task.

\section{Methods}

This research explores how service providers represent the needs of their constituents in face-to-face presentations to audiences who may positively affect these clients as well as examining the presentations' receptions. The study used participant observation of five presentations by senior and disabled service providers in various settings in the northeastern United States. The researcher examined efforts by service providers to educate practitioners and community 
members about the circumstances and needs of their clients with diminished capabilities. The field note analysis of the presentations addresses the consistency of socialization about those with functional limitations and how the presentations varied depending on the presenters, the audiences, and the populations being discussed. The study's research questions were:

1. How do service providers represent service users?

2. How do audience members react to these presentations?

3. What might explain different audience reactions to service provider presentations?

The observations enabled the researcher to experience the social context of these exchanges directly. Although it has been argued that participant observation is an ideal method for qualitative research[26] and provides the necessary context for interpreting informants' words and actions, little sociological research on this topic has used this method. Applying the strengths of participant observation was a particularly informative way to examine presentations by service providers about the growing populations they serve[27].

\subsection{Context and Settings}

Qualitative participant observation research was conducted at three convenience-sampled sites with three differing audiences: a home care agency (where I volunteered), a state university, and a public meeting at a town's council on aging in the suburbs of a large New England city.

\section{The Home Care Agency}

All Seasons (a pseudonym) is a private, nonprofit home care agency that serves regional "seniors, people with disabilities and those who provide care." Staff members, who specialize in such areas as health care, mental health care, protective services, personal care (bathing and dressing assistance), and support services (e.g., meals, transportation, laundry), provide "information, referral, in-home assessments, caregiver education, and care coordination services." Three of the five events observed were held at this agency.

\section{Town Council on Aging Symposium}

The symposium was a public event sponsored by the town's council on aging focusing on home safety and incorporating exercise into weekly activities to promote personal health and safety. It was divided into two parts: (1) a presentation by local university researchers on aging, their research, and current technological advances and (2) a presentation by an occupational therapist and fitness instructor who consulted with the local council on aging about home safety.

\section{University Disability Services Event}

a university commission held a panel discussion of undergraduate students with disabilities so they could share their experiences with others.

\subsection{Data Collection}

Presentations endorsed by organizations represent an ideal vision shared by the organization's members, or at least by its leadership. Nevertheless, presentations showcased different sorts of presenters; researchers served as presenters on two of the five occasions, health care practitioners gave presentations on two others, and students with disabilities were panelists in another. In addition to the involvement of different types of presenters, a number of different stakeholders were also involved as audience members. Because all presentations included question and answer sessions, it was possible to learn how presentations related to audience member experiences, beliefs, and interests. Observation of audience members throughout presentations further indicated their interests and reactions. Audience questions seemed particularly useful in revealing the issues and concerns of attendees, whether they were service providers, university staff wondering how to be more helpful, or laypeople seeking information useful to themselves or their loved ones.

\subsection{Data Analysis}

A grounded theory approach was used for data analysis because of my desire to enter the field with as few preconceived notions as possible, and because I could not predict how my findings might differ by setting. The analysis categorized the words and behaviors of event participants and compared emergent themes between presentations. To produce generalizable theoretical claims based on empirical data[28] the researcher took extensive notes at each presentation. These were typed into field notes, with concluding memos about emerging areas of interest and reflective comments, as recommended by Emerson, Fretz, and Shaw[29].

Field notes, asides, and memos were categorized by hand using open coding. When content or theoretical literature seemed relevant, it was also noted. I did not seek out definitions of disability until analysis was completed. After deriving a preliminary list of codes, three presentation content codes were tested for intercoder reliability by reviewing five pages of observation field notes with a sociology colleague. Although my fellow coder thought the initial definitions were clear, we did not always apply them in the same ways. As a result, we discussed definitional wording choices that would remove ambiguity. After coding was reconciled and definitional modifications were made, I applied focused coding to the remaining observation field notes to identify patterns and variations in how service

On the main campus of a public university in New England, providers represented their service users overall. 


\section{Findings}

The findings of the study presented below correspond sequentially, to each of its three research questions.

\subsection{How Do Service Providers Represent Service Users?}

Field note analysis identified three themes common to each presentation: organic limitations, situational limitations, and sensitivity toward service users. Organic limitations comprise a decreased ability to perform a desired/needed task or function because of a subject's cognitive, physical, and/or social incapacity or diminished capacity. Situational limitations reflect decreased ability to perform a desired/needed task or function as a result of factors aside from one's own structural limitations, such as employment discrimination. Sensitivity toward service users manifested in respect for the service user or interactions with them that nullified their disabilities

\section{Organic Limitations}

Organic limitations, generally discussed at the outset of each presentation, sometimes described general problems experienced by all members of the population and sometimes were illustrative examples. Although describing organic limitations that caused service users to require more assistance was an understandable way to convince audiences of the importance of their presentations, presenter statements about these limitations could be stigmatizing. This was most evident in the food safety presentation, in which the presenter said, "Why is food safety important? We are dealing with a high-risk population. Why are they at high risk? Because they're elderly." Differentiating between the audience ("I'm assuming you're healthy") and the elderly signaled that being elderly was a "high-risk" category. This conveyed to service providers that elderly people are weak in ways that reduced them "from a whole and usual person to a tainted, discounted one"[25]. This sort of service user generalization however was the exception. Overall, presentations highlighted individuality and challenging circumstances by emphasizing situational limitations or ways people could act sensitively toward service users.

\section{Situational Limitations}

After establishing clients' organic limitations, service providers described situational limitations their clients experienced. Situational limitations were social gaps in information or support that made daily living more cumbersome or dangerous. Regardless of their cause, situational limitations arise from breakdowns of social integration. Sometimes an absence of a support network is the complicating factor (e.g., "What is most difficult is if there isn't active family, someone lives alone and is at risk because there are limits to what you can and can't do" (researcher and Alzheimer's service provider). At other times, situational limitations stem from social isolation, as described by a panelist with Asperger's responding to a question about bullying: "In middle school, I had one teacher and she didn't do anything to discipline kids, so my mom got involved." Worse still is abuse by those physically and emotionally close to a service user, as explained at the Protective Services presentation: "It's easy for a perpetrator to say to a victim with diminished capacity that no one will believe their account." These excerpts reveal the influence of social context on service user quality of life.

\section{Sensitivity to Service Users}

Information is not the only thing community members need to level the playing field for those with organic limitations. Recommendations and models of interaction with service users varied across presentations. In the Alzheimer's presentation, the speaker proposed we communicate in ways that emphasize positive emotions and are sensitive to patients diminishing capacities in other areas. In this way, he emphasized the positive influence we can have while reminding us of the dwindling ways we can expect to meaningfully communicate.

\section{Distribution of Themes}

As emergent themes were reviewed (Table 1), it became apparent that while all service provider presentations acknowledged some service user impairment (organic limitations) that they emphasized situational limitations or sensitivity to service users as much, or more often. Though presentations varied as to which other theme was more emphasized, neither the topic, the setting (home care agency or public), nor the attendance type (mandatory, optional, or partially incentivized) alone could explain this variation.

Table 1. Service Provider Themes and Descriptive Features of Each Presentation

\begin{tabular}{|c|c|c|c|c|}
\hline Presentation Topic & Setting/Attendance Type & Organic Limitations & Situational Limitations & $\begin{array}{c}\text { Sensitivity } \\
\text { to Service Users }\end{array}$ \\
\hline Alzheimer's & Home care agency Mandatory & $31 \%$ & $31 \%$ & $39 \%$ \\
\hline Protective Services & Home care agency Mandatory & $14 \%$ & $68 \%$ & $18 \%$ \\
\hline Food Safety & Home care agency Optional & $36 \%$ & $57 \%$ & $7 \%$ \\
\hline Living with Disabilities & Public university Optional & $31 \%$ & $40 \%$ & $29 \%$ \\
\hline Aging Loved Ones & Town council on aging Optional & $22 \%$ & $29 \%$ & $49 \%$ \\
\hline & & $24 \%(44)$ & $46 \%(84)$ & $31 \%(55)$ \\
\hline
\end{tabular}




\subsection{How Did Audience Members React to Presentations?}

To help determine whether audience members internalized the intended socialization messages, audience member actions, such as applause, lingering to speak with presenters, participation in presentation activities, and interactions with presenters, were taken into consideration. Attendance numbers were not entirely appropriate because the populations from which prospective audiences originated were of vastly different sizes and because attendance requirements varied. Because applause can be normative in a particular setting, it is also an unreliable measure of authentic audience sentiment. Evidence of interest in helping the targeted populations was therefore better demonstrated by such actions as audience members lining up to ask questions, as occurred at both the Protective Services and Alzheimer's presentations.

Expressions of interest, acceptance, or approval were also demonstrated during presentations. For example, audience interest became clear from observing reactions to the occupational therapist's ways of controlling the body to help us "live safe," as opposed to controlling the home environment portion of her Aging Loved Ones presentation. At the end of her home environment discussion, one third of the audience members' hands shot up when she asked if there were any gardeners in the audience. A few minutes into her discussion on the importance of exercise, however, people began to move their bags or handouts onto their laps, type on their cell phones, or even leave the event.

\section{Nature of Audience Members' Stance toward Service Users}

\section{Types of Questions}

As with attendance, the number of questions asked at a presentation could be a misleading measure of engagement. For instance, the Protective Services presentation, which would appear to be the most well received according to applause and lingering attendees, elicited just five audience questions, whereas there were fifteen questions at the Food Safety presentation. The nature of questions posed at the Food Safety presentation however were a combination of jokes (e.g., "So there's no 5-second rule?"), self-interested queries (e.g., "can you tell us any foods less acidic we can eat?"), or general questions (e.g., "Are there any foodborne illnesses that you don't recover from?"), instead of pertaining to the home care agency's prepared meal delivery program for consumers (e.g., "What do [staff and volunteers who serve meals] do with [the prepared meals]?"). In contrast, the smaller quantity of questions at the Protective Services presentation focused on the frequency of a particular type of abuse (e.g., "How often do you find abuse is retaliatory?") or how to handle a specific situation (e.g., "What would you do"?). In other words, the number of questions audience members asked did not dictate the extent to which they demonstrated interest or likely application; looking at the nature of questions, however, showed how and for whom the information might be used.

\section{Revelations from Interactions between Presenters and Audience Members}

Audience members' attitudes toward service users became apparent from their questions and from exchanges with service-providing presenters. Two stances that audience members demonstrated toward service users were sympathy and protectiveness.

Sympathy: The Alzheimer's disease presenter generated sympathy for family caregivers and care recipients with case studies and a role-play exercise. In one scenario a man with dementia mistook his closet for a bathroom. In another, a daughter took her mother to a restaurant without realizing her mother had forgotten to put a dress on under her coat. Attendees gasped and laughed at first, demonstrating their emotional engagement, but also demonstrated cognitive engagement by actively taking notes and eagerly answering presenter follow-up questions. In the role-play experience, the presenter asked, "If I say to you, 'You took my pocketbook,' how would you respond?" In both cases, this presenter involved his audience by presenting information about scenarios involving service users and offering successful actions that could be used to resolve them.

Protectiveness: The optional home care agency Food Safety presentation was markedly different from the more popular mandatory ones in the tenor of the exchange between the audience and the presenter. Although part of the attendee response could have been due to the presenter herself, who stuck more closely to her slides than did other presenters, spoke more quickly, and responded curtly or not at all to some questions, audience members nevertheless demonstrated dedication to their service users.

In one exchange the presenter began to quickly brush over discussion of service user allergies telling the audience, "I believe you had a training before on allergies...The main reason we have to worry is because we don't make accommodations in our meals... because the caterer may swap out foods." As she moved to the next slide and began speaking about the caterer's responsibility however, one woman raised her hand to see if she could ask a question about allergies. In response, the presenter dismissively replied, "If allergies are obvious, we can tell them to avoid [certain] meals, but [they] can get sick." Unsatisfied with this answer however one audience member insisted, "If the allergens are life-threatening, warn them though." In this example, attendees appeared to be more protective of service users than did the presenter, even though all were service providers.

\section{Varied Levels of Engagement}

In contrast to home care agency presentations, exchanges between presenters and audience members at the public and voluntary town and university presentations showed more fluctuating levels of engagement. At the Living with Disabilities presentation, disinterest manifested in a number of ways, including showing up more than 15 minutes late, 
faculty underrepresentation (as one of the few audience participants noted), and a reluctance to ask questions or interact with panelists afterward. Moreover, there were only two moments of spontaneous positive audience response: both bursts of laughter in response to a student panelist's complaints about difficult courses. These moments of fellowship only temporarily bridged the interaction gap between audience members and panelists that otherwise characterized the presentation.

The public Aging Loved Ones' Safety at Home presentation likewise elicited more fluctuating levels of engagement than the homecare agency presentations. Attention to presenters at this event changed depending on the topic being discussed, but it had the widest range of reactions, including early departures, laughter, oohs and ahs, audience requests, suggestions, and definitional questions that implied attendee identification with "aging loved ones." Despite their demands on presenters, these audience members behaved like pure consumers, attentive to products that could improve "the quality of life for older adults and those who care for them" but less attentive to activities, such as exercises or research, targeted to older adults.

\subsection{Possible Explanations for the Difference in Audience Reactions to Service Provider Presentations}

To understand why audience reactions varied, I investigated what each presentation asked of its audience members. I considered the social roles of audience members relative to the service users who were the focus of each presentation. It seemed logical to consider what was asked of audience members because the themes of situational limitations and sensitivity appeared linked to how much action was being proposed. Because social role, setting, and attendance requirements alone did not correspond to the themes emerging from the presentations, I looked to my observation notes for patterns in audience members' appearing to accept or reject presenters' socialization efforts. I found that a) social roles actors in an audience occupied at each presentation may have influenced their identification with service users and b) some impression management occurred at the Aging Loved Ones' Safety presentations, where attendees plainly disassociated themselves from service users.

\section{What Was Asked of Audience Members?}

Each presentation expected different behavior from attendees. The town Council on Aging's Aging Loved Ones' symposium was described as having invited: "[a local researcher] to show us what new technology is available to help elders live comfortably at home... [as well as a] licensed Occupational Therapist ... showing practical solutions for home modifications." The first presenter began by describing three ways to "live safe" (technology, control of body, and control of the home), but ended by saying that "all have to be voluntary." The deferential tone that characterized this symposium asked the least of any presentations' audience members.

The Food Safety presentation was announced as: "[the agency's] own [staff member] will speak in regard to Food Safety" and asked that attendees tell agency consumers to avoid meals to which they may be allergic. This home care agency staff training focused on proper handling and preparation of food because the agency provides prepared meals for homebound seniors and disabled adults. One of my volunteer coordinators said she attended because she cooked, and that the other did not attend because she did not. The presenter reinforced the dual benefits of this event at the outset when she said the presentation might be helpful in our personal lives as well. Still, an employee attending it would no doubt be expected to be more aware of food hazards their clients may encounter, than non-attendees.

The Protective Services presentation was required for all home care agency staff because staffers are mandated by law to report suspicions of domestic violence. After a general overview, the presentation focused on elder abuse, which was especially relevant for an agency that helps older adults and disabled people live in their homes instead of institutions. Nevertheless, there was little for attendees to do but learn what signs to look for, how to make a report, and how to support victims emotionally. Aside from instructions on dealing with reports of abuse, these three things constituted the only advice given.

The email message announcing the Living with Disabilities presentation to university faculty, staff, and students did not address audience role at all: "panel discussion with [university] students . . . living with disabilities...panel members ... will discuss how their disability impacts them. Following their presentations, there will be opportunities for questions..." Faculty members were encouraged to "support" the event by requiring students to attend and "write about the experience as homework"; vouchers would be available at the door "to prove attendance." This incentivization was successful because students appeared to comprise about $75 \%$ of the audience.

The mandatory agency staff training on Alzheimer's had an explicit goal linked to audience members' caregiving roles. After an overview, it focused on "how best to support caregivers committed to caring for loved ones at home." This topic was of particular interest to the home care agency. The expectation that audience members would attend, learn, and apply the lessons of this presentation was the most directly stated of any presentation.

\section{Social Identities of Audience Members and Their Stance Relative to the Service User Population}

Before examining the relationship, between audience members' socialization expectations and their reactions to presentations, successful socialization to service users should be described. According to Goffman, everyone is a performer and audience member concurrently[24], so it was not surprising that I observed evidence of only one behavior modification in all the presentations. Nevertheless I acquired supplementary evidence that Protective Services had the 
greatest impact of the three homecare agency presentations.

Apparent Socialization through Greater Understanding, Sympathy, and Peer Pressure

The most successful socialization occurred when an audience member, who seemed unsympathetic to abuse victims at the start of the Protective Services presentation, ceased complaining by its conclusion. By playing a videotaped victim interview and initiating a group dialogue, the presenters directly addressed the cause of the audience member's frustration; namely, not understanding why victims stay in abusive relationships. The presenter asked the audience to think about their reactions to the video: Sometimes our reactions say, 'I can't believe...you stayed after that?'

A brief video documenting the experience of a man who was abused by his wife substantiated the presenters' approach. Before the video, the audience was told to consider some reasons that the victim might stay; after the video, those reasons are discussed. Many audience members offered answers based on the victim's testimony, but none expressed incredulity. In this way the presenter socialized attendees to both perceive and treat victims as deserving of sympathy and compassion in her agency.

\section{Apparent Rejection of Socialization Efforts}

My review of presentation announcements revealed that attendees at mandatory presentations demonstrated the most consistent interest and concern for service users. Though the Food Safety presentation offered little instruction to help service users, attendees demonstrated concern for their welfare.

Motivations of the Aging Loved Ones' attendees might have differed from what the event planners expected because the audience appeared to be older adults themselves. It seemed likely that they were attending the presentation to improve their own self-care. Similarly, the majority of attendees at the Living with Disabilities presentation were students motivated largely by the attendance vouchers offered for course credit. Although many trickled in late and only one asked a question, their presence was most marked by their laughter at jokes about courses and by the lines for vouchers at the end of the presentation instead of at the snack table. In this way, although some may have had disabilities themselves or been interested in learning more, students in the audience stuck to their student role almost exclusively focused on courses and grades.

\section{Discussion}

\section{How Goffman Might Explain Acceptance or Rejection of Presentation Socialization Efforts Explicit Self-identification as a Provider or Helper versus the Helped}

Because all presentations about how to interact with service users were educational, they presumed some ignorance of the population, implying that attendees were not service users themselves. At the home care agency presentations, audience members were present explicitly in their roles as helpers. In the town hall and university settings, where attendees' identities were not as clear, many made a point of identifying themselves to distinguish them from service users. At no presentation did any audience member ever explicitly identify as someone seeking an accommodation for themselves per se.

\section{Impression Management to Avoid Stigma}

Impression management seemed to play out in two ways. First, when service providers displayed indifference or frustration with service users, as in the Food Safety and Protective Services presentations, they were confronted with the more normative expressions of concern expected from those in the role of service provider. In both presentations, group reinforcement of role expectations curbed any repetition of these gaffes. Second, when audience member identities were less clear, attendees resisted identification with service users.

Whether by directly identifying oneself as someone helping others or implying it by denying classification as a user of services for older adults or students with disabilities, these presentation attendees appeared to disassociate themselves from these labels and, when the service users were present, from those who had them. Audience member behavior at the service provider presentations therefore was consistent with Goffman's description of the stigmatized person's "work at presenting an uncontaminated or 'unspoiled' identity when in the co-presence of others from whom they must hide their stigma"[25].

\section{What Might Explain Different Audience Reactions to Service Provider Presentations?}

It appeared that audience members' desire to present themselves as possessing an unspoiled identity may have involved "defensive practices" when their identity could be ambiguous to observers. Acceptance of caretaking socialization efforts for example seemed related to prior acceptance of the caretaking role, professionally, as a volunteer, or as a family caregiver. As a provider of support, one is more likely assumed to be whole. Those who attended service provider presentations in roles that did not imply providing services demonstrated less interest in service users and willingness to follow recommendations. This behavior could have been a way to distinguish themselves from those with the discounted identities of service users, who by definition are designated as requiring some assistance. For audience members who are not prospective service users, such distancing may be more a reflection of the prejudices of the larger society[24].

This study is limited by its sample and data collection method. All research sites are in New England and all settings are disproportionately affluent. My university, though public, is one of the more expensive public 
universities in the nation. Similarly, the catchment area of the volunteer agency contains some of the wealthiest communities in the state. City and town assessments of residential taxes ranged from just under $\$ 4$ billion to $\$ 18$ billion in 2011[30]. The town meeting also took place in one of these communities. Thus, the experiences of attendees who have disabilities, are aging, and/or are in poor health might at least have been in a good financial position at one time. In this way, they did or still might have access to resources in communities that have the economic potential (if not the will) to provide more support to community members[31]. In addition, this study was limited to brief observation periods in different settings instead of occurring in one context over an extended period, as is more customary. Although none of the presentations attended lasted for more than 2 hours, I was a member of the communities I observed in four of the five presentations (e.g., the home care agency and university).

Despite its limitations, the study produced some useful findings. For instance, both internal organizational and external presentations addressed three themes: organic limitations, situational limitations, and sensitivity to service users. These themes are consistent with the description of impairments that service users face, and express service provider concerns parallel to MacLeod and Stadnyk's[16] health and social practitioner considerations in assessing those "living at risk." Overall, service users were represented positively, as people with limitations deserving of understanding, sympathy, and fair treatment. In four of the five presentations, service providers represented service users as people with organic and situational limitations beyond their control who were deserving of care. In the one instance when a presenter was most dismissive of service users, the service provider audience emphasized their value to the presenter!

Audience member reactions appeared to depend on the roles of audience members in the particular setting where a presentation occurred. Audience members had more positive reactions, including attentiveness to and involvement in presentation activities when presenters shared personally relevant experiences, offered home safety modifications to an older adult audience, or talked about case studies with fellow service providers. I contend that audience members were particularly pleased with the presentation of information and techniques when they aligned with the audience's social role at the time of the presentation. For those who attended presentations in the role of service provider or caregiver of an aging loved one, what was presented could enhance their performance as caregivers. Home care agency staff and volunteers were receptive to socialization because of their pre-selected roles in the caregiving home care organization.

In contrast, at presentations to non-service provider audiences, reactions varied based on the extent that audience members expressed interest in acquiring information they could apply in non-stigmatizing ways. They took notes and asked questions most often in regard to good self-care (e.g., the health-conscious attendees at the Food Safety presentation and the home improvements and adaptations for an aging loved one instead of for themselves). Because the few Living with Disabilities attendees who asked questions usually identified themselves as wanting to support students with disabilities, their questions were targeted to school services for such students. Notably, audience members disengaged or distanced themselves when content (i.e., exercise or socializing with panelists) entailed that they identify with roles that were less familiar and/or comfortable.

\section{Conclusions}

The primary goals of this study were to explore how service providers present service users, how audiences react to their presentations, and what might explain different attendee reactions. Though content analyses of public policy documents[15], service providers interviews [16,17], and observations of internal organizational meetings[17] have been conducted previously, I did not identify prior research in which presentation observations were made to both organizational and external audiences, to enable comparisons.

Service provider presentations about older adults or students with disabilities showed some similarities in how they portrayed service user and in the sorts of sensitivity and behaviors asked of audience members. By taking an inductive approach, I was able to confirm prior conceptions of how those working in the field define disability and found similar service provider considerations to those expressed in prior research[16].

This research is relevant because it seeks to identify how to make service provider presentations more effective. My findings suggest that audience attitudes and behavior may be more likely to change as a result of service provider presentations when audience members' identities are already positively linked to service users. Presenters must be sensitive to possible impression management desires of audience members who are trying to "pass" for "normal." This may be important because presentations about service users may provide a vehicle for self-help for those who do not wish to disclose needs that could signal a discreditable identity. For example, at the Living with Disabilities event, the presenter opened with the fact that about $5 \%$ of students on campus were known to have a disability. Given this, it seems likely that some student attendees may have had disabilities and were not there only for course credit but were trying to "pass" as "normal" disaffected students. Lastly, although immediate behavior changes in front of nonservice providing peers might not be visible, changes in attitudes and behavior may be more evident in other settings. Thus, even a presentation that does not appear to have been successful in changing behavior may be capable of doing so; the right setting might just be required, in which a social actor is comfortable enacting a less practiced script. My 
primary volunteer coordinator's acknowledgement that she perceived and acted differently toward service users after attending the Protective Services presentation substantiates this interpretation.

Although all the presentations observed included sensitizing messages, the self-interests of audience members appeared to vary, as revealed through the abundance or dearth of attendees, or questions at the end of presentations. The differing levels of audience engagement and its alignment with attendee self-interests is consistent with prior theory on prejudice and discrimination that contends that discrimination occurs when individuals fail to perceive those in other groups as similar to themselves[12]. Although intergroup contact has been found to reduce discrimination[10,11], without the underlying perception of similarity, positively modifying behavior towards "out-group" members is unlikely[12].

As prior literature on patient, family member, and service providers has previously demonstrated, even when groups have seemingly compatible interests, the perception of difference can lead to different perspectives about how to address common issues[16,17,18]. Clark[15] further demonstrates how even key stakeholders in the aging and disability communities reacted very differently regarding home (health) care policy in Canada. As the aging community had been mentioned regularly in government policy discussions, its members generally appeared satisfied with proposed health care changes that experts repeatedly criticized as inadequate. In contrast, because of society's lack of equalizing efforts, members of the disability community, whose concerns were less explicitly addressed and who have historically been marginalized, advocated for more comprehensive services consistent with what experts said would increasingly be required in future. Clark's argument that the aging community in Canada could benefit from joining efforts initiated by the disability community would be equally true in the United States[15]. Such a movement might help members of both communities feel less stigmatized and reluctant to divulge their identities, as appeared to be the case for some attendees at the non-service provider presentations I observed. The patient empowerment movement, for instance, argues for universal client or consumer decision-making power; in its inclusivity it has the potential for more far-reaching benefits than separate special interest groups may obtain alone.

Further research on service provider presentations across a broader range of settings, which incorporates follow-up interviews with attendees about their motivations for attending and any modifications in knowledge, understanding, and attitudes, would help to verify and extend the findings of this study. Although it is important to expand the repertoires of service providers, it would also be useful to identify ways to enlist those who are not already professionally invested in the welfare of others.

Although an increasing number of older adults are expected to experience some form of disability, the interests of the aging and disability communities have continued to be treated separately by many at individual and institutional levels. Disability community organizations[15] and researchers[19] demonstrate how mainstream exclusion marginalizes people with disabilities and negatively affects their quality of life. Without integrating their concerns, we can anticipate the potential marginalization of this growing percentage of our population. If service providers cannot generate concern for and promote positive action by other community members for the clients they serve, it will be more difficult for the public to support beneficial policies.

As Kenny[32] explains about language in policy discourse, "words used highlight some beliefs and values and obscure others. The framing of the discourse therefore influences the construction of meaning" (p.5). The current research therefore attempted to extend the analysis of "talk" about service user needs to the "walk" in service provider presentations in public and private settings. Until a sufficient percentage of the U.S. public realizes and advocates for the common interests of all people, as the disability community has[33], we are at risk of continuing to base social policies not on what would benefit the majority but on the wants and needs of those who are most influential[34,35].

\section{REFERENCES}

[1] United States Census Bureau. Nearly 1 in 5 People Have a Disability in the U.S., Census Bureau Reports, 2012. Online available from

https://www.census.gov/newsroom/releases/archives/miscella neous/cb12-134.html

[2] World Health Organization. World Report on Disability. Geneva, Switzerland. World Health Organization. "Disabilities." World Health Organization. Online available from http://www.who.int/topics/disabilities/en/

[3] C. Mathers, D. M. Fat, J. T. Boerma. The global burden of disease: 2004 update, World Health Organization, Geneva, 2008.

[4] U.S. Department of Health and Human Services and U.S. Department of Labor. The future supply of long-term care workers in relation to the aging baby boom generation: Report to Congress, Washington, DC: Office of the Assistant Secretary for Planning and Evaluation, 2003. Online available from http://aspe.hhs.gov/daltcp/reports/ltcwork.htm

[5] R. B. Friedland. Caregivers and long-term care needs in the $21^{\text {st }}$ century: Will public policy meet the challenge? Georgetown University Long-term care financing project, 2004. Online available from ltc.georgetown.edu

[6] U.S. Census Bureau. Facts for feature. Online available from http://www.censusgov/Press-Release/www./releases/archives/ facts the_features_special-editions $/ 006105 \mathrm{html}$

[7] J. Harwood. 2016 Politics Drive Talk on Entitlements. The New York Times, May 7, 2015.

[8] K. Snell. Senate passes Obamacare repeal, Planned Parenthood defunding bill, putting Republicans on record, Washington Post, December 3, 2015. 
[9] D. Engster. Strategies for Building and Sustaining a New Care Movement, Journal of Women, Politics \& Policy, Vol. 31, 289-312, 2010.

[10] G. W. Allport. The nature of prejudice, Addison Wesley, Reading, MA, 1954.

[11] T. F. Pettigrew, L. R. Tripp. A Meta-Analytic Test of Intergroup Contact Theory, Journal of Personality and Social Psychology, Vol. 90, No. 5, 751-783, 2006.

[12] R. W. Clement, J. Kruger. Liking persons versus liking groups: a dual-process hypothesis, European Journal of Social Psychology, Vol. 28, 457-469, 1998

[13] C. Pereira, J. Vala, J. P. Leyens. From infra-humanization to discrimination: The mediation of symbolic threat needs egalitarian norms, Journal of Experimental Social Psychology, Vol. 45, 336-344, 2008.

[14] H. H. Keller, J. J. M. Dwyer, V. Edwards, C. Senson, H. G. Edward. Food Security in Older Adults: Community Service Provider Perceptions of Their Roles, Canadian Journal on Aging, Vol. 26, No. 4, 317-328, 2007

[15] P. G. Clark. Understanding Aging and Disability Perspectives on Home Care: Uncovering Facts and Values in Public-Policy Narratives and Discourse, Canadian Journal on Aging, Vol. 26, Suppl. 1, 47-62, 2007.

[16] H. MacLeod, R. Stadnyk. Risk: 'I know it when I see it': how health and social practitioners defined and evaluated living at risk among community-dwelling older adults, Health, Risk \& Society, Vol. 17, No. 1, 46-63, 2015.

[17] S. McDermott. Professional judgements of risk and capacity in situations of self-neglect among older people, Aging and Society, Vol. 30, 1055-1072, 2010.

[18] B. Launay. Approache sociologique de la qualite des services a domicile: impact des dynamique relationelles sur les definitions de qualite des serives a domicile: points de vue de la personne agee, du proche-aidant et de l'auxillaire familiale et sociale, Doctoral Dissertation. University of Montreal, 2008.

[19] C. McFarlane, I. Brookes, K. McInnes, B. Cross. Platforms, Plateaus, and String: A Disability Diverse Research Team's Account of Spatial Challenges and Strategies Within Research Dissemination Spaces, Qualitative Inquiry, Vol. 19, No. 10, 794-806, 2013.

[20] T. P. Shippee. "But I Am Not Moving": Residents' Perspectives on Transitions Within a Continuing Care Retirement Community, The Gerontologist, Vol. 49, No. 3, 418-427, 2009.

[21] H. Blumer. Symbolic Interactionism: Perspective and Method, Prentice-Hall, Englewood Cliffs, NJ, 1969.
[22] G. H. Mead. Mind, Self, and Society, University of Chicago Press, Chicago, 1934.

[23] C. H. Cooley. On Self and Social Organization, University of Chicago Press, Chicago, 1902/1998.

[24] E. Goffman, The Presentation of Self in Everyday Life, Anchor Books, New York, 1959.

[25] E. Goffman. Stigma: Notes on the Management of Spoiled Identity, Simon \& Schuster, Inc., New York, 1963.

[26] N. Denzin, Y. Lincoln. Introduction: Entering the field of qualitative research. In: N. Denzin and Y. Lincoln, editors, The Landscape of Qualitative Research, Sage, Thousand Oaks, 1998.

[27] Institute of Medicine (US) Committee on Disability in America; Field MJ, Jette AM, editors. The Future of Disability in America, 3, Disability Trends. National Academies Press (US), Washington (DC), 2007. Online available from http://www.ncbi.nlm.nih.gov/books/NBK11437/

[28] I. Tavory, S. Timmermans. Two cases of ethnography: Grounded theory and the extended case method, Ethnography, Vol. 10, No. 3, 1-21, 2009.

[29] R. M. Emerson, R. I. Fretz, L. L. Shaw. Writing Ethnographic Fieldnotes, University of Chicago Press, Chicago, 1995.

[30] C. M. Douglas. Assessing Bay State taxes: A town and city breakdown, Boston Business Journal, April 1, 2011. Online availablefromhttp://www.bizjournals.com/boston/datacenter/ mass-taxes-town-and-city-breakdown.html?appSession $=5010$ $35643911002 \&$ RecordID $=\&$ PageID $=2 \&$ PrevPageID $=2 \&$ cpip age $=1 \&$ CPIsort Type $=$ asc $\&$ CPIorderby $=$ Percent_commercial

[31] M. D. King, P. S. Bearman. Socioeconomic Status and the Increased Prevalence of Autism in California, American Sociological Review, Vol. 76 No.2, 320-346, 2011.

[32] N. Kenny. What's fair? Ethical decision-making in an aging society. Research Report F/44. Canadian Policy Research Networks, Ottawa, 2004. Online available from http://www.cprn.org/doc.cfm?doc=776\&l=en

[33] A. Y. Drewett. Social rights and disability: The language of "rights" in community care policies, Disability and Society, Vol. 14, 115-128, 1999.

[34] E. Armstrong, D. Carpenter, M. E. Hojnacki. Whose Deaths Matter? Mortality, Advocacy, and Attention to Disease in the Mass Media. In P. Conrad, editor. The Sociology of Health and Illness: Critical Perspectives, Worth Publishers, New York, 2012.

[35] A. Gawande. The Cost Conundrum. The New Yorker, June 1, 2009. 